\title{
20
}

\section{Graduate Student Mentors: Meeting the Challenges of the Ongoing Development of Graduate Student Instructors}

\section{Chris O'Neal}

University of Michigan

\section{Jennifer Karlin}

South Dakota School of Mines and Technology

Training and mentoring Graduate Student Instructors (GS Instructors) at large institutions presents three challenges to instructional developers: 1) training numerous GS Instructors from multiple departments, 2) the vast array of duties GS Instructors need training in, and 3) the continual sophistication of GS Instructors. Here we describe how the College of Engineering at the University of Michigan has met these challenges through the use of Graduate Student Mentors (GS Mentors). GS Mentors are experienced GS Instructors who are trained to mentor and advise their peers. We discuss how the GS Mentors are selected, trained, and supervised, and how they have helped to meet the challenges outlined above.

The training and development of Student Instructors (GS Instructors; otherwise known as teaching assistants) presents a number of challenges to large, research-oriented institutions that must employ numerous GS Instructors to teach laboratories and recitations, provide office hours, and even deliver some lectures. These challenges include 1) the logistics of training, supporting, and monitoring a large number of GS Instructors from multiple departments and backgrounds, 2) providing adequate training time and coverage of the 
many duties that any given GS Instructor may have, and 3) accommodating the changing needs of these GS Instructors as they gain experience and begin to teach more advanced courses with more involved duties. While these challenges are by no means unique to large, research-oriented institutions, this context makes them very visible. In this chapter we discuss the ways in which one institution, the College of Engineering at the University of Michigan (UM) (hereafter referred to as $\mathrm{CoE}$ ), has met these challenges through the use of a centrally organized group of Graduate Student Mentors (GS Mentors).

\section{Graduate Student Mentors: Helping to Meet the Challenge}

In order to address the challenges of preparing GS Instructors, CoE trains and supervises a group of experienced GS Instructors who serve as Graduate Student Mentors to the rest of the GS Instructor population. The GS Mentors are centrally organized through the Office of the Associate Dean for Graduate Education, and are trained and supervised by staff from UM's Center for Research on Learning and Teaching (CRLT). This is in contrast to other models of peer mentoring used at UM which are typically departmentally based. Currently, there are ten GS Mentors each term, with each GS Mentor being accountable for 20 to 30 GS Instructors. While centrally organized, GS Menturs are responsible for GS Instructors in only one to three departments; this allows GS Mentors to get to know one cadre of GS Instructors very well, instead of having their time and energy used to coordinate logistics within multiple departments.

The GS Mentor program in CoE was founded on the belief that developing CoE GS Instructors could benefit from the unique guidance, support, and expertise that peer mentors provide. While all GS Instructors have access to mentoring from their advisors or other professors in their department, the peer mentor relationship provides a safe venue for exploration of teaching strategies and discussion of teaching problems that is absent of fear of judgment from one's professorial superiors. GS Mentors in CoE are trained to mentor in a facilitative way, a model that appeals to their own sense of their role and approaches the collegial style of supervision preferred by most GS Instructors (Prieto, 1999). Additionally, the nature of the peer mentor-mentee interaction is such that it allows both individuals to give and receive benefits (Bollis-Pecci \& Walker, 1999), so that it is a valuable learning experience for the GS Mentors themselves. 


\section{Roles of the Graduate Student Mentor}

GS Mentors serve a number of roles in CoE. They may serve as mentors, evaluators, trainers, and other roles as the GS Mentor encounters unexpected situations within their departments that require support and expertise. This multiplicity of roles calls for a wide set of skills and abilities in the GS Mentor, and presents challenges for their preparation and training.

First and foremost, GS Mentors serve as confidential mentors to GS Instructors in their assigned departments. GS Mentors consult on issues ranging from classroom management challenges, implementation of new teaching and learning strategies, and professor/GS Instructor conflicts. Unless required as part of a GS Instructor's initial training, consultation with a GS Mentor is always at the behest of the GS Instructor. GS Mentors contact their GS Instructors to offer these services either via email or face-to-face contacts at multiple points throughout the term.

GS Mentors also offer valuable classroom feedback services to their GS Instructor clients. GS Mentors may observe a class and share their observations with the GS Instructor afterwards, they may film the class and then conduct a video observation consultation afterwards, or they may conduct a midterm student feedback (also known as a small group instructional diagnosis) in which the GS Instructor leaves the classroom and the GS Mentor talks to the students about how the class is going, then shares the students' feedback with the GS Instructor. As with general consultation, all of these feedback services are confidential to ensure the comfort and engagement of the GS Instructor. Because GS Mentors are peers of the GS Instructors they serve, they are able to present feedback in a nonthreatening way that is easily implementable by the instructors.

GS Mentors also participate in the GS Instructor Teaching Orientation that all new CoE GS Instructors are required to attend. This 12-hour orientation is centrally coordinated and run by the university's Center for Research on Learning and Teaching. The orientation involves GS Mentor-led sessions on organizing and teaching lab and discussion sections, teaching problem solving techniques, multicultural teaching and learning issues, grading/assessment issues, and practice teaching, among others. Besides presenting training sessions in which they share their expertise on particular teaching and learning topics, the GS Mentors use orientation to meet with their new GS Instructors and to lay the groundwork for future mentoring. GS Mentors are also often called on to staff workshops and discussions on teaching throughout the term and often organize get-togethers for their assigned GS Instructors. Using the GS Mentors in this role provides CoE with a trained, 
organized group of committed and experienced teachers who share a common background and disciplinary perspecrive with the instructors they are training.

\section{Selection and Training of Graduate Student Mentors}

The GS Mentor selection process is competitive. Applicants are selected based on teaching experience, demonstrated dedication to teaching, and demonstrated interest in helping their peers with teaching and learning issues. The current group of GS Mentors for the 2002-2003 academic year has over 17 years of collective reaching experience and 26 combined terms of GS Mentor experience. Hiring of the GS Mentors is coordinated so that new GS Mentors are working with experienced mentors each term. Additionally, the college makes every effort to hire a GS Mentor pool that reflects the diverse ethnic and multicultural makeup of the GS Instructor population the GS Mentors will be serving.

$\mathrm{CoE}$ attempts to hire GS Mentors from every department within the college, but this is not always possible. Because more GS Mentors are recruited from some departments than others, GS Mentors are often serving in a department other than their own. This can be seen as a drawback of the centralized model of organizing teaching mentors, since GS Mentors outside their own departments spend much of their time establishing trust with their client base before they can begin their work as instructional developers. CoE attempts to overcome this situation by organizing early and frequent interactions between GS Me.ttors and their GS Instructors (e.g., at new GS Instructor orientation) and by emphasizing the role of the GS Mentors as facilitators on thinking about pedagogy, rather than content experts. Experience from the CoE GS Mentor program suggests that it is better to hire GS Mentors based on their promise as consultants and mentors, rather than based on their departmental affiliation.

Because the nature of instructional development calls on skills that even experienced instructors may not have mastered, all GS Mentors go through a series of training workshops at the beginning of their tenure. New GS Mentors attend workshops on observing classes and giving feedback, and are specifically trained in observing classes and giving feedback through the use of midterm student feedbacks and videotape observation. This training lasts approximately ten hours and emphasizes the skills that the GS Mentors are most likely to employ during their tenure. This training also teaches the GS Mentors how to build the bonds of respect and communication that are necessary for peer mentoring relationships (Bollis-Pecci \& Walker, 1999). Additionally, all of the GS Mentors meet as a group twice monthly for continual staff development and to discuss issues that have come up in their own consulting. 
Staff development topics include sessions on promoting retention of underrepresented groups in engineering, instructional technology, discussing case studies to practice consulting skills, and recent advances in engineering education. Throughout the entire term, GS Mentors are mentored to recognize which issues they can comfortably consult on (teaching and learning issues, classroom problems, interactions with students) and which issues should be referred to a campus professional (emotional issues, issues of harassment or abuse, etc.).

The one-on-one, peer mentoring nature of the GS Mentor-GS Instructor interaction directly addresses many of the challenges described above. In the next three sections, we discuss these challenges in detail and highlight how the GS Mentor program has addressed them.

\section{Challenge One: Training Large Numbers of GS INSTRUCTORS From MULTIPLE DeparTMENTS}

Training GS Instructors at large institutions often represents a logistical challenge, due to the large numbers and varying disciplinary backgrounds of the GS Instructor population. For example, in CoE, there are approximately 225 GS Instructors spread across 13 departments. This presents a particularly diverse pool of instructors to train and develop, an issue which is complicated by the fact that at any time, $70 \%$ or more of the GS Instructors in the college are in their first or second term in the classroom (see Table 20.1). This means that a sizable segment of the GS Instructor population is in dire need of basic training that is no longer appropriate for the other segment of more experienced instructors. Data presented in all tables is from a bi-annual survey given to all GS Instructors in the College of Engineering. As of the fall $2002 \mathrm{term}$, the survey has been administered five times.

\section{TABLE 20.1}

Percentage of CoE GS Instructors Arranged by Number of Terms of Experience

\begin{tabular}{cccccc}
\hline $\begin{array}{c}\text { Number of } \\
\text { Terms }\end{array}$ & $\begin{array}{c}\text { Fall } \\
\mathbf{2 0 0 0}\end{array}$ & $\begin{array}{c}\text { Winter } \\
\mathbf{2 0 0 1}\end{array}$ & $\begin{array}{c}\text { Fall } \\
\mathbf{2 0 0 1}\end{array}$ & $\begin{array}{c}\text { Winter } \\
\mathbf{2 0 0 2}\end{array}$ & $\begin{array}{c}\text { Fall } \\
\mathbf{2 0 0 2}\end{array}$ \\
\hline $1-2$ & $77 \%$ & $82 \%$ & $79 \%$ & $72 \%$ & $73 \%$ \\
$3-6$ & $19 \%$ & $18 \%$ & $21 \%$ & $28 \%$ & $24 \%$ \\
$7+$ & $4 \%$ & $0 \%$ & $0 \%$ & $0 \%$ & $3 \%$ \\
\hline
\end{tabular}

Data is from a voluntary survey presented to GS Instructors each term and does not account for the total GS Instructor population of CoE. 
Expecting departments to train their own GS Instructors is not always feasible in CoE, where one department contains one-third of the college's total GS Instructor population and other departments have only one or two GS Instructors total. Some of these smaller departments do not have the resources to carry out departmentally based training for their own GS Instructors, even though they have small numbers of GS Instructors to train. Instead, CoE centrally organizes GS Instructor training so that all GS Instructors, regardless of their home department, receive the same level and quality of training. This centralized training model includes the New GS Instructor Orientation described earlier, and the GS Mentors themselves. This centralized model allows the college to set a strong, minimum training standard; assure quality in the preparation and presentation of that standard; and maintain programs for continuous improvement.

This centralized approach allows CoE to offer basic training to new GS Instructors (in the form of the orientation) and continual support to more advanced GS Instructors (through the GS Mentors) without the logistical and financial burden of continued large-scale training. Because GS Mentors are assigned to one, or at most a few, departments, they represent a particularly flexible and personalized model of continual training that allows us to reach GS Instructors in all departments equally, in a way that large-scale one-sizefits-all efforts like the orientation cannot. Because interaction with the GS Mentors is voluntary, they allow CoE to provide continual training and support to those GS Instructors who desire it. This efficient model of instructional development is particularly relevant at a time when many instructional development efforts are facing budget cuts.

\section{Challenge Two: Providing Training for GS Instructors With Multiple Duties}

While often presented as fairly simple assignments, graduate teaching assistantships at large institutions are actually complicated, involved positions that require a number of skills (an assertion supported in general studies of GS Instructor duties) (Gappa, 1993). Duties GS Instructors perform range from leading discussions to grading papers to running labs and even giving lectures in large classes (see Table 20.2 for a complete listing of GS Instructor duties in $\mathrm{CoE}$ ). Seventy-five percent of GS Instructors in $\mathrm{CoE}$ report having at least four separate and unique duties associated with their teaching assignment every term. Some GS Instructors report having as many as ten duties each term. 
TABLE 20.2

\section{List of Duties Performed by GS Instructors in CoE}

\begin{tabular}{lll}
\hline 1) Hold office hours & 7) Teach a discussion section & Maintain web site \\
2) Grade exams & 8) Attend class & Write exams \\
3) Grade labs or projects & 9) Give lectures & Write labs \\
4) Hold review sessions & Answer student emails & Proctor exams \\
5) Grade homework or papers & Write homework & Determine grading \\
6) Write homework solutions & Teach a lab & schemes \\
\hline
\end{tabular}

Duties are ordered from most common to least common. Duties without a corresponding number were listed only occasionally by GS Instructors.

It is difficult for a single orientation event (such as the one described earlier) to adequately train all of these duties in a single day. GS Instructor orientation in $\mathrm{CoE}$ offers GS Instructors their choice of a number of concurrent sessions, but even so, GS Instructors inevitably leave orientation with only a modicum of training in some of the duties they will have to perform. Again, the personalized, one-on-one services that the GS Mentors offer helps to meet this challenge. GS Mentors are often called on after the term has begun to work with GS Instructors who need more help with their specific duties. Because they are able to work in-depth with instructors, GS Mentors can deliver training and support in context, something that the orientation cannot.

\section{Challenge Three: Continual Training for a Maturing Population}

The continual development of GS Instructors also presents a conceptual challenge to trainers, as the basic training that proves sufficient for a novice instructor is rarely appropriate for GS Instructors who have progressed to the level of junior colleagues with more advanced duties. Even though $\mathrm{CoE}$ has very high turnover of its GS Instructor population, there is a fairly stable core of returning, experienced GS Instructors each term (approximately 30\%) who need more advanced training and support. For example, in $\mathrm{CoE}$ a first term GS Instructor is sometimes asked to teach a lab section where their duties may include running labs and grading lab reports, and then be asked to be a grader in their next term. GS Instructors returning for a second year of teaching may even be asked to teach a discussion section or their own lecture in some cases. Since GS Instructors are only required to attend one orientation event at the 
very beginning of their tenure, they face these new duties with no additional training or preparation beyond that which they have independently sought out from peers and other campus resources. In an extension of their role as advanced trainers of specific duties, GS Mentors can help an experienced GS Instructor adjust to a new teaching position, identify areas for growth, and work with that GS Instructor to fill in those areas. This model is time effective for the GS Instructors and they seem more willing to meet for one-on-one with a GS Mentor than to attend large-scale retraining events.

Experienced GS Instructors are also constantly changing in the way they think about teaching. Nyquist and Sprague (1998) describe a model of GS Instructor development that conceptualizes GS Instructor progression from senior learners to colleagues-in-training to junior colleagues. This model sheds light on the changes that GS Instructors may go through in terms of their basic concerns, discourse level, approach to authority, and approach to their students. Accommodating these changes presents a challenge to GS Instructor trainers. Experienced GS Instructors require a different kind of training and support than novice GS Instructors, and this is complicated by the fact that progression through the Nyquist-Sprague model is highly individualized. As with their attention to changing GS Instructor duties, GS Mentors can address the changing perspectives of maturing instructors in a one-on-one environment in a way that large-scale training cannot. By having GS Mentors provide this consultation, $\mathrm{CoE}$ is able to offer a service to instructors that is flexible to the varying needs and developmental levels of the GS Instructors. The bond of trust that is needed for GS Mentors to work effectively with GS Instructors establishes the groundwork for GS Mentors to deliver their support in a way that makes the most sense for GS Instructors at certain stages of development.

\section{Evaluation of the Current GS Mentor Program}

As seen in Table 20.3, the current GS Mentor program has been very successful. The majority $(91 \%-100 \%)$ of CoE GS Instructors are aware of the program, even if they have not yet taken advantage of their GS Mentor's services. The $40 \%$ or more of the GS Instructors in each term who have used their GS Mentor have rated their GS Mentor highly (94\%-98\% rated their GS Mentor as excellent or good), and report that they learned a variety of skills and knowledge from the interaction, such as learning of a peer group with whom to share experience; awareness of new resources; improvement of their skills; and the knowledge that, as one respondent stated, "I'm not alone, fumbling through the world of teaching." Even those GS Instructors who 
have not actively pursued engagement with their GS Mentor have reported appreciation for their GS Mentors' presence, knowing that the GS Mentor is there as a resource should he or she be needed.

TABLE 20.3

Evaluation of the Current Program

\begin{tabular}{|c|c|c|c|c|c|}
\hline & $\begin{array}{c}\text { Fall } \\
2000\end{array}$ & $\begin{array}{l}\text { Winter } \\
2001\end{array}$ & $\begin{array}{c}\text { Fall } \\
2001\end{array}$ & $\begin{array}{c}\text { Winter } \\
2002\end{array}$ & $\begin{array}{c}\text { Fall } \\
2002\end{array}$ \\
\hline Aware of program? & $91.2 \%$ & $98.0 \%$ & $100 \%$ & $100 \%$ & $98.9 \%$ \\
\hline Had contact? & $42.1 \%$ & $45.1 \%$ & $66.1 \%$ & $53.3 \%$ & $43.0 \%$ \\
\hline $\begin{array}{l}\text { Rated GS Mentor } \\
\text { excellent or good } \\
\text { (of those who rated } \\
\text { their GS Mentor) }\end{array}$ & $93.8 \%$ & $95.0 \%$ & $95.7 \%$ & $97.9 \%$ & $97.6 \%$ \\
\hline \multicolumn{6}{|c|}{$\begin{array}{l}\text { "Aware of program" indicates what percentage of GS Instructors polled reported } \\
\text { knowing about the GS Mentor program. "Had contact" indicates what percentage of } \\
\text { GS Instructor polled reported having contact of some sort with their GS Mentor. } \\
\text { "Rated GS Mentor..." indicates what percentage of those GS Instructors reporting } \\
\text { contact with their GS Mentor rated their performance as excellent or good. }\end{array}$} \\
\hline
\end{tabular}

\section{Challenges and Opportunities for Program Growth}

While a centrally managed mentorship group like the GS Mentors has a number of advantages over departmentally based ones, it does present some challenges (see Mintz, 1998, for a complete review of centralized training programs). First and foremost, communicating and publicizing the value of the GS Mentors is a continual, difficult process. Despite a steady stream of emails from the program managers and the associate dean's office, a number of graduate students are uncertain of the role of the GS Mentors, and some faculty, mistrustful of faculty development efforts, discourage their GS Instructors from taking advantage of this service. In the College of Engineering, we have attempted to rectify these constraints in several ways. For new and experienced GS Instructors, we heavily advertise the GS Mentors at the centralized new GS Instructor orientation and at the various departmental welcomes at the beginning of the year. For faculty, we do a number of presentations on the value of the GS Mentor program in departmental and higher level meetings across campus. For both groups, we continually emphasize the confidential nature of the GS Mentors in all our communications and presentations. 
Second, because some departments are not represented in the GS Mentor group, it is often a struggle for mentors outside of those departments to reach GS Instructors within those departments. As mentioned earlier, we have attempted to recruit GS Mentors from all departments, but some are too small to furnish GS Mentors, and others, while large, have not had enough graduate students interested in the position. This imbalance has hampered our efforts at impacting CoE's largest department, Electrical Engineering and Computer Science (EECS), which has four GS Mentors assigned to it, only one of which is currently enrolled in EECS. Recruitment of GS Mentors from EECS is also complicated by the fact that most EECS graduate students are well funded. Additionally, there are some programs (e.g., the first year design classes) which have no graduate students, but are instead served by GS Instructors from many departments. We continue to aggressively recruit for GS Mentors in EECS and the other large departments, but until the culture of teaching changes substantially in these departments, it is likely that we will always have to draw on GS Mentors from other departments to serve them.

Third, quality control is a constant priority for the program. Considering that the GS Mentors are relatively new to teaching themselves and may, therefore, not be qualified to give others teaching advice is important to consider. However, as with the peer consulting programs described in Petrulis, Carroll, and Skow (1993), the GS Mentors primarily facilitate their clients' thinking about their own teaching; they do not prescribe a "correct" way of teaching and thus need not be experts on all potential pedagogical issues their GS Instructors might encounter. Bimonthly meetings with the GS Mentor group and Center for Research on Learning and Teaching staff provide an opportunity to share opinions and feedback on how consultations should be handled and skills that can be implemented to handle them. Furthermore, delicate situations are directly supervised by the CRLT staff who manage the group. A survey evaluating the GS Mentors' performance is sent out every term, and GS Mentors receive that feedback along with guidance on how they might improve their own consulting. To further our quality control efforts, in future academic years the program is instituting more frequent individual check-ins with the GS Mentors, as well as issuing satisfaction surveys to "clients" within weeks of their interaction with a GS Mentor.

\section{Conclusion}

This chapter documented one way that a peer mentoring program can be implemented, that is, via a centralized model. It is not the only way that a peer mentoring group can work, and there are numerous examples of departmentally 
based models. UM's own College of Literature, Science, and the Arts is one example of a successful departmentally based system where peer mentors are organized by their home department and serve only the GS Instructors of that department. Departmentally based models of peer mentoring exceed their centralized counterparts in at least one dimension: The training/mentoring is delivered in the context of the department and is therefore more in line with the culture and goals of the department than a centralized model ever could be. Centralized models, on the other hand, maintain a minimum level of quality of training/mentoring in all departments and benefit from inter-departmental exchange between the trainers/mentors.

The decision to institute a centralized or departmentally based model of peer mentoring hinges on a number of issues. Administrators must consider the costs of each model, the level to which resources are already shared between departments, the presence or absence of a shared vision between departments of how much teaching is valued, and the importance of a shared disciplinary context. The decision to implement a centralized model of peer mentoring in CoE was largely based on concern over some departments' ability to adequately commit to and support peer mentors and the comparatively low cost of managing them centrally. Regarding costs, we have found that we get exceptionally high quality service from our GS Mentors without the intensive, long-term training that other peer mentoring programs have used. We ascribe this to excellent selection of the GS Mentors and extensive mentoring of them by professional staff during the term.

The Graduate Student Mentor group at the University of Michigan's College of Engineering has been extremely effective at meeting the instructional development needs of a large, diverse GS Instructor population. It can be seen as a good model for similar centralized efforts at comparable institutions with large numbers of GS Instructors from very different departments. However, perhaps more important than the many roles described earlier, the GS Mentor group serves as a visible reminder that teaching is valued and important in CoE. By modeling a culture that "teaching is OK," (as discussed in Winternitz \& Davis, 2000), the GS Mentors give graduate students in CoE the chance to value and take pride in their own teaching efforts, opportunities that are all to often lacking at large research institutions.

As a final note, let us emphasize that the GS Mentor position is not simply a service role. The GS Mentors receive valuable advanced training in teaching which places them at the vanguard of the next generation of higher education instructors. Consulting and mentoring build a host of additional skills that will complement their teaching and make them valuable commodities to 
institutions that are emphasizing teaching more and more (Petrulis et al., 1993). The GS Mentors are an advanced group of outstanding teachers who take pride and joy in the opportunity to share their experience and wisdom with their peers.

\section{ACKNOWLEDGMENTS}

This chapter, and the entire GS Mentor program, would not have been possible without the strong support of Deans Stella Pang and James Bean in the College of Engineering. Their commitment to graduate student instruction is a model for leadership in this area. We would also like to thank the numerous cohorts of GS Mentors who have worked tirelessly to improve teaching and learning at the University of Michigan.

\section{References}

Bollis-Pecci, T. S., \& Walker K. L. (1999). Peer mentoring perspectives in GTA training: a conceptual road map. The Journal of Graduate Teaching Assistant Development, 71$), 27-37$.

Gappa, L. (1993). The teaching associate program: A collaborative approach. The Journal of Graduate Teaching Assistant Development, 1(1), 25-32.

Mintz, J. A. (1998). The role of centralized programs in preparing graduate students to reach. In M. Marincovich, J. Prostko, \& F. Stout (Eds.), The professional development of graduate teaching assistants (pp. 19-40). Bolton, MA: Anker.

Nyquist, J. D., \& Sprague, J. (1998). Thinking developmentally about TAs. In M. Marincovich, J. Prostko, \& F. Stout (Eds.), The professional development of graduate teaching assistants (pp. 61-88). Bolton, MA: Anker.

Petrulis, R., Carroll, S., \& Skow, L. (1993). Graduate students as instructional consultant: case studies from two universities. The Journal of Graduate Teaching Assistant Development, I(2), 85-93.

Priero, L. R. (1999). Teaching assistants' preferences for supervisory style: Testing a developmental model of GTA supervision. The Journal of Graduate Teaching Assistant Development, Q(3), 111-118.

Winternitz, T., \& Davis, W. E. (2000). Lessons learned during five years of the UC Davis program in college teaching. The Journal of Graduate Teaching Assistant Development, $\pi(2), 69-75$. 


\section{Contact:}

Chris O'Neal

3300 School of Education Building

University of Michigan

610 E. University Street

Ann Arbor, MI 48109-1259

Voice (734) 763-4418

Fax (734) 647-3600

Email_coneal@umich.edu

Jennifer Karlin

South Dakota School of Mines and Technology

501 East St. Joseph Street

Rapid City, SD 57701

Voice (605) 394-1271

Fax (605) 394-2409

Chris O'Neal is an Instructional Consultant at the Center for Research on Learning and Teaching at the University of Michigan. A PhD in biology, he works with sciences, math, and engineering instructors, and runs numerous workshops and seminars on active learning and engaging students. He is the coordinator of the Graduate Student Mentors group at UM's College of Engineering as well as the team leader for the Center for Research on Learning and Teaching's Graduate Student Instructor Team.

Jennifer Karlin recently completed her $\mathrm{PhD}$ in industrial engineering at the University of Michigan. While there, she taught as both a teaching assistant and as primary instructor. She also worked for the Center for Research on Learning and Teaching as a Graduate Teaching Consultant (GTC). As a GTC, she co-coordinated the Graduate Student Mentor program and the new Graduate Student Instructor Orientation. She is now an Assistant Professor of Industrial Engineering at the South Dakota School of Mines and Technology 